\title{
The generalizability of context effects on word recognition: A reconsideration of the roles of parafoveal priming and sentence context
}

\author{
KEITH E. STANOVICH \\ Oakland University, Rochester, Michigan 48063 \\ and \\ RICHARD F. WEST \\ James Madison University, Harrisonburg, Virginia 22807
}

\begin{abstract}
In three experiments, subjects named target words preceded by congruous, incongruous, or neutral sentence contexts. There was no evidence that the recognition of the target word was affected by the semantic characteristics of a word presented immediately to the right of it. The nature of the preceding sentence context did affect target-naming speed. However, the magnitude of the context effect was considerably smaller in these experiments, in which nonterminal target words were used, than in previous experiments in which the target word was always the final word of the sentence, was highly predictable from the context, and was often semantically related to words in the sentence. The implications of these two findings for theories of reading and context effects are discussed.
\end{abstract}

In the last decade, an increasing number of investigators have focused their attention on the problem of how the presentation of a prior context affects word recognition, a question of much potential relevance to the study of the reading process. It has been firmly established that the presentation of a single word prime can speed the recognition of a related target word (Becker \& Killion, 1977; Fischler, 1977; Fischler \& Goodman, 1978; Meyer \& Schvaneveldt, 1971; Meyer, Schvaneveldt, \& Ruddy, 1975; Neely, 1976, 1977; Schvaneveldt \& McDonald, 1981). In addition, several investigators (e.g., Fischler \& Bloom, 1979, 1980; Kleiman, 1980; Schuberth \& Eimas, 1977; Schuberth, Spoehr, \& Lane, 1981; Stanovich, 1981; Stanovich \& West, 1979, 1981; West \& Stanovich, 1978, 1982) have found that the processing of the last word of a sentence is faster when it is preceded by a congruous sentence context than when it is preceded by an incongruous sentence context. The purpose of the present paper is to explore the generality of the context effects

This research was supported by National Science Foundation Grant BNS80-20594 to Keith E. Stanovich and by the James Madison University Program of Grants for Faculty Research. James H. Neely is thanked for his many helpful comments on our research program. The authors wish to thank Nancy Kelly, Dorothy Feeman, Andrea Bubka, Monica Travers, and Greg Nichols for assistance in data collection. Requests for reprints should be sent to Keith E. Stanovich, Department of Psychology, Oakland University, Rochester, Minnesota 48063. that have been demonstrated in the sentence context situation.

The target word in all of the sentence context studies cited above has been the terminal word of the sentence. In this way, and in others, the situations that have been used to assess sentence context effects have been unrepresentative of average text. For example, in many experiments the target word has been deliberately chosen for its high predictability. In other experiments (e.g., Kleiman, 1980; Stanovich \& West, 1979, 1981), words in the sentence context have had strong associative and semantic relationships with the target word. Gough (Note 1) has argued that perhaps in our rush to create powerful experimental designs in order to test theoretical models, we may have overloaded our stimulus materials so much that our sample estimates of context effects are not applicable to the normal reading situation. In the experiments to be reported here, we began to address this question by attempting to assess the effect of a sentence context on a nonterminal word, using a paradigm that has been shown to be sensitive to various types of context effects on the sentence-final word. Thus, we employed the pronunciation paradigm of Stanovich and West $(1979,1981)$ and assessed the effects of a sentence context on adjectives and nouns that modified the final word of the sentences. The paradigm was modified only to the extent that following the sentence context, two words (a terminal noun preceded by an adjective or noun modifier) appeared. 
The subject's task was to name the first word just as they had named the terminal word in previous experiments. The modifiers in Experiment 1 were not constrained to be highly predictable or highly associated with words in the context.

The design of Experiment 1, a modification of the Stanovich and West $(1979,1981)$ paradigm, was one that allowed the investigation of another important issue in the area of context effects on ongoing word recognition. Although we usually think only of the words that precede the word currently being fixated as the context that could affect its processing, it is possible that words in the right parafovea or periphery could affect the processing of a word currently under fixation. In several experiments, Underwood $(1976,1977,1980$, 1981) has found that the processing of a stimulus under fixation was affected by the semantic characteristics of a word that appeared to the right of it. Thus, it is possible that context effects on ongoing word recognition during reading result from words to the right of the current fixation as well as from the words preceding the target word. This issue is easily investigated by slightly modifying the design already described. Since the modifier is the target word that is named, the terminal noun can be manipulated in order to assess whether the naming of the modifier is influenced by changes in the word immediately to the right of it. Specifically, the lexical status of the terminal noun can be manipulated in order to assess whether modifier naming is faster in a condition in which the terminal noun is a word that is congruous with the rest of the sentence, as opposed to a control condition in which it is a nonword.

In summary, two separate issues can be simultaneously addressed by slightly modifying a design that has been useful in examining context effects on the recognition of the final word of a sentence. Before reporting two experiments, we will briefly review the evidence concerning context effects on nonterminal words and priming from words in the right parafovea, so that the relation of these questions to general issues in the reading literature is clearer.

\section{Effects of Preceding Context on Word Recognition}

A strong position on how context affects word recognition is taken by the theorists responsible for the so-called top-down models of the reading process (e.g., Goodman, 1976; Hochberg, 1970; Levin \& Kaplan, 1970; Smith, 1978). In these models, reading is conceptualized as a process of hypothesis generation and confirmation. Readers supposedly predict upcoming text and only minimally sample visual information in order to confirm predictions. According to these models, it is this minimal sampling of visual information that accounts for the rapid reading of the fluent reader.

At first glance, the experimental literature on singleword priming and sentence context effects would seem to provide strong support for the account of ongoing word recognition given by the top-down models. In both paradigms, large context effects have been demonstrated. However, as mentioned in the introduction, the primes in the single-word studies have been either strongly related to or predictive of the target words. There are also several problems with the sentence context literature. As previously mentioned, the targets employed by most investigators have been nouns that were always the final word of the sentence. Thus, there was never any uncertainty about the position or form class of the word. More important, Fischler and Bloom (1979) found that contextual facilitation of word processing occurred only when the mean predictability of the target word was greater than $90 \%$. Word processing was facilitated only when the target word was much more predictable than the average word in most texts (see below). Stanovich and West (1981) have found contextual facilitation effects for target words that were much less predictable than the Fischler and Bloom (1979) stimuli. However, the target words in their studies had an atypically high number of semantic and associative relationships with words in the sentence contexts (see also Kleiman, 1980).

In summary, an analysis of existing sentence context experiments suggests that the large context effects observed may have resulted from the overloading of the stimuli with highly predictable sentence-final nouns and/or targets that were strongly related to context words. There is some limited empirical evidence that supports this conjecture. Using a continuous lexical decision task and a self-paced reading task (admittedly, an experimental situation quite different from the pronunciation and lexical decision paradigms that form the bulk of the literature), Mitchell and Green (1978, Note 2) found no contextual effects on words occurring in the interior of sentences. The materials came from published short stories and novels. Alford (Note 3) used a pronunciation task to test for contextual effects on the fifth word of sentences that were drawn from books and newspapers. He observed a context effect of only $19 \mathrm{msec}$, much smaller than that observed in previous studies that employed predictable terminal nouns as targets (although the use of only a four-word context without the previous sentence may have biased Alford's study toward obtaining a smaller effect than usual).

From the writings of the top-down theorists, one gets the impression that predicting upcoming words in sentences is a relatively easy, natural, and highly accurate activity. However, several different empirical studies of the issue (Aborn, Rubenstein, \& Sterling, 1959; Miller \& Coleman, 1967; Perfetti, Goldman, \& Hogaboam, 1979; Rubenstein \& Aborn, 1958; Gough, Note 1; Alford, Note 4; Gough, Alford, \& Holley-Wilcox, Note 5) have all indicated that upcoming words in text are not very predictable. Across a variety of subject popula- 
tions, texts, sentence positions, and other relevant variables, one salient fact emerges. Given a prior context, a reader's accuracy in predicting the next word in the passage is between $20 \%$ and $35 \%$. Approximately three times out of four, the reader's guess is wrong. Using SAT-type passages, Alford (Note 4) found that a little more than four guesses were needed before the average word was guessed correctly (because of the scoring procedure used, Alford's figure is, if anything, an underestimate of how many guesses were needed). Thus, there appears to be some evidence that there is a discrepancy between the predictability levels of the stimuli used in sentence context experiments and those in natural text. Although our experiments have been quite useful in testing theoretical models, because of the oversampling of predictable sentence-final nouns, the results of experiments in the literature probably should not be used as parameter estimates of the magnitude of the context effects occurring in actual reading.

\section{Can Words to the Right of Fixation \\ Affect the Processing of the Currently Fixated Word?}

To begin, this question must be differentiated from a very similar and related issue that has received some investigation. Several studies (e.g., McClelland \& O'Regan, 1981; Paap \& Newsome, 1981; Rayner, McConkie, \& Zola, 1980) have addressed the question of whether various types of information are extracted from a word in the parafovea so that the processing of that word is facilitated when it is brought into the fovea on the next fixation. In contrast, in this paper, we are concerned with the question of whether aspects (in particular, semantic aspects) of a word to the right of fixation can affect the processing of the word currently being fixated. The available evidence relevant to the latter question is indeed ambiguous. While there are theoretical reasons for expecting such effects, and while such effects have been demonstrated in experimental paradigms that bear similarities to the reading situation, other experiments have failed to reveal an effect.

Certain facts about attentional and unattended processing must be true in order for the parafoveal priming of a currently fixated word to be even a theoretical possibility. Since most of a reader's attention is focused on the fovea, rather than the parafovea, for parafoveal priming to take place, it must be possible for an unattended word to prime an attended one (or, at the very least, for a word receiving little attentional allocation to prime one toward which the bulk of attention is directed). There is now some evidence on this point. Several studies have been reported (e.g., Fischler \& Goodman, 1978; Fowler, Wolford, Slade, \& Tassinary, 1981; Marcel, 1978; McCauley, Parmelee, Sperber, \& Carr, 1980; Philpott \& Wilding, 1979) in which it has been shown that a stimulus that is presented under visual conditions so degraded that it cannot be reported can nevertheless affect the processing of a second attended word (but see Merikle, 1982). Perhaps more relevant to the issue under discussion is an experiment by Shaffer and LaBerge (1979). They found that even when sub. jects were told to ignore words that appeared above and below a target word, responses to the target word were affected by the semantic category of the unattended words.

Parafoveal priming of foveal words would appear to be precluded by the fact that the accumulation of parafoveal information is probably delayed relative to foveal information accrual (McConkie, 1979; Rayner, Inhoff, Morrison, Slowiaczek, \& Bertera, 1981; Schiepers, 1980). However, evidence that these timing considerations need not preclude the possibility of parafoveal priming has been reported by Kiger and Glass (Note 6). Using a single-word semantic priming paradigm, they found that the processing of a target word was facilitated even when its onset preceded that of the prime by $65 \mathrm{msec}$.

Bradshaw (1974) has reported that the interpretation of a tachistoscopically presented stimulus was affected by simultaneously presented flanking words that could not be reported. However, Inhoff (1982; Inhoff \& Rayner, 1980) has reported contradictory results. Underwood $(1976,1977)$ found that picture-naming latency was affected by semantic relationships between the pictures and words printed to the side of them. In a closer approximation to the actual reading situation, Underwood $(1980,1981)$ found that the processing of a fixated target word was affected by a simultaneously presented related word that was printed immediately to the right of the target word. In contrast, Paap and Newsome (1981) found that a related parafoveal prime did not speed the processing of a fixated word, even when the prime preceded the target in time. Clearly, there is some inconsistency in the results of experiments that bear on the issue of whether the semantic characteristics of words to the right of fixation can affect the ongoing processing of the word currently being fixated. In the experiments to be reported here, we attempted to collect some data on this issue using a task that mimics the reading situation to a greater extent than have the paradigms used in previous research.

\section{EXPERIMENT 1}

More is gained from combining the question of sentence context effects on nonterminal words with that of priming from words to the right of fixation than the mere efficiency of a factorial design. For reasons that should be obvious, given the previous review, the magnitudes of both effects under investigation could weil be small. It is possible that both sources of facilitation are insufficient, by themselves, to produce a detectable benefit in target processing. However, the priming from both sources may together be sufficient to induce 
a sizable target benefit. There is a precedent for such a finding in a study by McClelland and O'Regan (1981). It is thus not inconceivable that there could be an interaction between the effect of a sentence context and that of a word to the right of fixation.

In the Stanovich and West $(1979,1981)$ experiments, subjects named terminal nouns that were preceded by sentence contexts that were congruous, incongruous, or neutral with respect to the target. This design was altered in order to investigate the two issues previously discussed. The sentences from the appendix of Stanovich and West (1981) formed the basis for the stimuli of Experiment 1. Modifiers were inserted before the final noun of each sentence and the modifier-noun pair became the target stimulus. These pairs were presented as targets following congruous, incongruous, and neutral sentences, as before. However, subjects had to name only the modifier. The lexical status of the terminal noun was manipulated in order to investigate the issue of parafoveal priming. On one-half of the trials, the stimulus appearing to the right of the modifier was a nonword anagram of the noun that should have appeared. The lexical status of the stimulus to the right of the target was varied orthogonally with sentence congruity.

\section{Method}

Subjects. The subjects were 24 undergraduate psychology students recruited through a subject pool at James Madison University.

Stimuli and Apparatus. The 96 sentence contexts presented in Appendix A of the Stanovich and West (1981) paper were used as stimuli, along with the difficult set of terminal nouns from that appendix. A word, either a noun (e.g., church aisle) or an adjective (e.g., baggy trousers), that modified the terminal noun was inserted into each sentence (e.g., "The whale was injured by the harpoon" became "The whale was injured by the sharp harpoon"). Thus, the last three words of the sentences were the word "the," a word that modified the sentence's last word, and a noun that was congruous with the sentence's preceding words.

The 96 sentence contexts were presented to 17 college students (who did not participate in the experiment) as a cloze task in which they were to write down the two words that best completed each sentence. Across all contexts, the target modifier appeared $8.5 \%$ of the time as the modifier in the subject's best completion. An additional 24 subjects were presented with the 96 contexts followed by a blank and the terminal noun and were asked to supply a word for the blank that best completed the sentence. Across all contexts, the target modifier appeared as the subject's best completion $18 \%$ of the time. An effort was made to assess the strength of the relationship between the target modifier and the terminal noun and between the target modifier and words in the context. Two pairs of words for each sentence were constructed (the context word most strongly related with the target modifier was paired with the modifier, and the modifier was paired with the terminal noun) and randomly assigned to two lists. Thus, no word appeared more than once in a list and the two types of relationships (context-modifier and modifiernoun) were mixed within a list. Two separate groups of 22 subjects produced relatedness ratings for each list. Subjects made a judgment as to how related the words of each pair were on a $1-5$ scale, on which 5 indicated a high degree of relationship, 3 indicated a moderate degree of relationship, and 1 indicated no relationship. Across all pairs, the mean relatedness rating for context word/target modifier pairs was 2.81 , and the mean relatedness rating for target modifier/terminal noun pairs was 3.11. The difference between the two types of word pairs was statistically significant $(p<.01)$.

The sentences were organized into pairs (e.g., "The game warden fined the deer poacher" was paired with "The bodyguard drove the black limousine"). The last two words (the modifier and the noun) of each sentence were then deleted. The resulting incomplete sentences were used as sentence contexts, and the deleted two words were used as modifier-plus-word (MW) targets. A sentence context and an MW target were considered to be congruous when they had been derived from the same original sentence. A sentence context and an MW target were considered to be incongruous when they had been derived from opposite members of the original sentence pairs (e.g., "The game warden fined the" was incongruous with the MW target "black limousine"). A neutral context condition was created by presenting the incomplete sentence "They said it was the" before an MW target. Across all MW targets, the mean number of letters in the modifiers was 6.2 and the mean number of letters in the terminal nouns was 7.4. In addition to the MW targets, a set of modifierplus-nonword $(\mathrm{MN})$ targets was created by replacing the terminal noun in the MW targets with a nonword anagram (e.g., "deer poacher" became "deer eopcarh").

The stimuli were typed on $10.2 \times 12.7 \mathrm{~cm}$ cards in lowercase Letter Gothic font with an IBM Selectric II typewriter. One set of cards contained the sentence contexts, and another contained the targets. Approximately $70 \%$ of the contexts required two lines. In these cases, the final letter in the last word of the top line was always two spaces directly above the final letter of the sentence context. The stimuli were presented via a Scientific Prototype tachistoscope at a viewing distance of approximately $76 \mathrm{~cm}$. Five-letter words subtended a horizontal visual angle of approximately $.72 \mathrm{deg}$, and the space between words subtended a horizontal visual angle of approximately $.15 \mathrm{deg}$. The contexts and the targets were presented in separate fields of the tachistoscope and were aligned so that if both were presented simultaneously the stimuli looked like a complete sentence. There was normal spacing between the modifier and terminal letter string. On all experimental trials, sentence context offset was simultaneous with target onset. Target onset and timing were controlled by a button pushed by the experimenter that immediately caused the target to be displayed and simultaneously started a millisecond clock. When the subject responded verbally to the target, a voice-activated relay stopped the clock.

Prior to the collection of the data, the experimenter was given extensive practice in synchronizing the pushing of the control button with the articulation "the" (the context word that always immediately preceded the target). Of course, some time invariably elapsed between the subject's articulation and the experimenter's buttonpress. However, the experimenter tried to minimize this time by attempting, on all trials, to initiate his buttonpress with the articulation of "the" such that the button was activated as soon as possible after the end of the articulation of "the." The experimenter was instructed to develop a criterion so stringent that it occasionally resulted in his pressing the button during the articulation of "the," thus aborting the trial. There were only a few experimenter-aborted trials, but those that did occur were distributed approximately equally across all experimental conditions, indicating that the criterion was consistently applied.

Procedure. Subjects were individually tested in a session that lasted approximately $40 \mathrm{~min}$. Subjects were told to look into the tachistoscope and read aloud the sentence contexts that appeared. In addition, they were instructed to verbally respond to the targets as rapidly as possible when they appeared. Although a target consisted of both a modifier and either a word or nonword, the subjects were asked to name only the modifier. In addition, the subjects were told that only the vocal response to the modifier was timed, so they were free to read the contexts at a comfortable pace. 
Each subject received a random ordering of 12 practice trials consisting of two trials given under each of the six conditions formed by the factorial combination of context (congruous, incongruous, neutral) and target type (MW, MN). Following the practice trials, each subject received a random ordering of 72 experimental trials consisting of 12 trials given under each of the above six conditions. In the experimental trials, each subject saw a subset of 72 of the total population of 192 possible MW and MN targets. The assignment of targets from the total population was counterbalanced across subjects so that each target was read equally often under each type of context condition and target type. No subject saw the same target or sentence context more than once in the course of the experiment, and no subject saw more than one member of an MW-MN pair. When sentence contexts were used in incongruous context trials, the deleted terminal words from the original sentences were never seen by the subject.

\section{Results and Discussion}

Trials on which some type of experimental malfunction occurred (e.g., the vocal response was too soft for the relay setting, the experimenter aborted the trial by pushing the button too early) were dropped from the data analysis. Trials on which the subject articulated the wrong word, had a response time longer than $2,000 \mathrm{msec}$, or had a response time longer than 2.5 standard deviations above the mean for that condition were scored as subject errors and were also dropped from the analysis. The mean reaction times and the mean percentage of subject errors for all of the experimental conditions are displayed in Table 1. Also contained in Table 1 are the magnitudes of the overall context effect (the difference between the congruous and incongruous conditions), the facilitation effect (the difference between the congruous and neutral context conditions), and the inhibition effect (the difference between the neutral and incongruous conditions). All of the analyses that follow are based on the subject's mean reaction time in each condition.

An analysis of variance on the reaction times indicated that the effect of context condition was significant $[F(2,46)=4.17, p<.05]$, but neither the main effect of target type nor the Context Condition by Target Type interaction approached significance $(F<1$ in both cases). Planned comparisons indicated that the inhibition effect in the word condition was significant $(p<.025)$, but the inhibition effect in the nonword condition did not attain significance. Neither facilitation effect was significant.

Given that target type did not interact with context condition and that when collapsed across context conditions, the times in the word and nonword conditions were virtually identical, it appears that there is no evidence that the lexical status of the terminal noun affected the speed of word naming. The results regarding the effect of the preceding sentence context are easily summarized. The significant effect of context condition indicates that a prior sentence context can affect the processing of a nonterminal word that was not chosen for its high predictability or relatedness. However, the overall context effect averaged only $18 \mathrm{msec}$. Although significant, the magnitude of this effect is well below that observed in similar experiments that have assessed the effect of a prior context on the final word of the sentence (although the 7-msec overall context effect in the nonword condition may be somewhat of an underestimate due to the presence of a small context effect in the error rates). Depending on the difficulty of the target word, contextual effects in those experiments have varied between 40 and $120 \mathrm{msec}$. Thus, the results do reinforce the conjecture discussed in the introduction, that previous experimental designs have produced estimates of contextual effects that are not representative of the values that might be obtained from a wider sampling of materials and word positions. One aspect of the results that was puzzling was that the contextual effects that were obtained in Experiment 1 were manifested almost entirely as inhibition. In previous experiments with this paradigm (Stanovich \& West, 1979, 1981), a pervasive pattern of facilitation dominance had been found. Experiment 2, designed as a stronger test of whether parafoveal priming effects could be obtained in this paradigm, also provided an opportunity to see if this discrepancy with past results could be replicated.

Table 1

Mean Reaction Times in Milliseconds and Mean Percentage of Errors (PE)

\begin{tabular}{|c|c|c|c|c|c|c|c|c|c|}
\hline \multirow{3}{*}{$\begin{array}{c}\text { Parafoveal } \\
\text { Stimulus }\end{array}$} & \multicolumn{6}{|c|}{ Context Condition } & \multirow{3}{*}{$\begin{array}{l}\text { Facili- } \\
\text { tation }\end{array}$} & \multirow{3}{*}{$\begin{array}{l}\text { Inhibi- } \\
\text { tion }\end{array}$} & \multirow{3}{*}{$\begin{array}{c}\text { Overall } \\
\text { Context } \\
\text { Effect }\end{array}$} \\
\hline & \multicolumn{2}{|c|}{ Congruous } & \multicolumn{2}{|c|}{ Neutral } & \multicolumn{2}{|c|}{ Incongrous } & & & \\
\hline & RT & $\mathrm{PE}$ & RT & PE & RT & $\mathrm{PE}$ & & & \\
\hline & \multicolumn{9}{|c|}{ Experiment 1} \\
\hline Word & 615 & 1.7 & 618 & 1.7 & 644 & 1.0 & 3 & 26 & 29 \\
\hline \multirow[t]{2}{*}{ Nonword } & 624 & 2.1 & 617 & 2.4 & 631 & 4.5 & -7 & 14 & 7 \\
\hline & \multicolumn{9}{|c|}{ Experiment 2} \\
\hline Word & 550 & 2.6 & 578 & 4.7 & 569 & 3.9 & 28 & -9 & 19 \\
\hline \multirow[t]{2}{*}{ Nonword } & 557 & 1.8 & 585 & 2.9 & 579 & 3.9 & 28 & -6 & 22 \\
\hline & \multicolumn{9}{|c|}{ Experiment 3} \\
\hline Word & 578 & .5 & 612 & 3.7 & 601 & 3.1 & 34 & -11 & 23 \\
\hline Nonword & 577 & 2.1 & 613 & 2.6 & 591 & 5.7 & 36 & -22 & 14 \\
\hline
\end{tabular}




\section{EXPERIMENT 2}

It is possible that Experiment 1 provided only a weak test of whether parafoveal priming effects during ongoing reading can be obtained. Although the stimulus sentences were constructed so that the terminal noun was always congruous with the preceding sentence, and several sentences contained nouns that were semantically related to or associated with their modifiers (e.g., "The preacher spread the holy gospel"), many sentences had modifiers and final words that were only weakly related (e.g., "The house was destroyed by the powerful tornado"). If a word in the right parafovea can prime a word under fixation, such an effect would probably be due to some type of automatic spreading activation in semantic memory. Thus, it could be argued that parafoveal priming was precluded in Experiment 1 because, across stimuli, the average semantic relationship between modifier and noun was simply too low. In Experiment 2, we attempted a stronger test of the effect of a parafoveal prime by replicating Experiment 1 with a different set of materials that were "loaded" with semantic relationships.

\section{Method}

The subjects were 32 undergraduate students recruited through a subject pool at Oakland University.

Approximately $25 \%$ of the sentences used in Experiment 1 were judged by the experimenters to have strong modifier-noun relationships and were retained in Experiment 2. The remaining sentences were altered to increase the semantic and/or associative relationship between the modifier and noun. Sometimes this was done by choosing a new modifier. The relationship in other sentences was strengthened by using the easy, rather than the difficult, terminal noun from Appendix A of Stanovich and West (1981). In some cases, both the modifier and the noun were changed (e.g., "The house was destroyed by the powerful tornado" was changed to "The house was destroyed by the hot fire"). Approximately $30 \%$ of the preceding contexts were also changed so as to maintain congruity with the target word pair. Across all of the MW targets, the mean number of letters in the modifiers was 6.4 and the mean number of letters in the terminal nouns was 5.7. The MN targets and the neutral context were constructed as in Experiment 1.

The 96 sentence contexts were presented to 22 students (who did not participate in the experiment) as a cloze task in which they were to write down the two words that best completed the sentence. Across all contexts, the target modifier appeared $5.8 \%$ of the time as the modifier in the subject's best completion. An additional 22 subjects were presented with the 96 contexts followed by a blank and the terminal noun and were asked to supply a word for the blank that best completed the sentence. Across all contexts, the target modifier appeared as the subject's best completion $11.9 \%$ of the time. Two groups of subjects ( $\mathrm{N}=26$ and 22 , respectively) made relatedness judgments, as described in Experiment 1. Across all pairs, the mean related ness rating for context word/target modifer pairs was 2.93 and the mean relatedness rating for target modifier/terminal noun pairs was 3.15 . The difference between the two types of word pairs was statistically significant $(p<.05)$. The mean rating of the modifier-noun pairs was only slightly higher than that obtained for the pairs used in Experiment 1, even though those in Experiment 2 were chosen to be more highly related. This was probably the result of the fact that the pairs from each experi- ment were not mixed together but, instead, were given to separate groups of subjects who then may have adopted different subjective anchoring points in order to keep their average rating around 3.

The stimuli were presented on a BMC CRT monitor with a refresh cycle of $16.7 \mathrm{msec}$ under the control of an Apple II microcomputer. A Mountain Hardware clock and a Lafayette Instruments voice key interfaced with the computer enabled the collection of vocal reaction times. All letters were uppercase and were presented at a viewing distance of $64 \mathrm{~cm}$. Five-letter words subtended a horizontal visual angle of approximately $1.88 \mathrm{deg}$, and the space between words subtended a horizontal visual angle of approximately $.45 \mathrm{deg}$. In Experiment 2, the sentence remained on the screen after target onset. Experimental sessions lasted approximately $25 \mathrm{~min}$. All other aspects of the design, including target onset, timing, number of trials, and counterbalancing, were as in Experiment 1.

\section{Results}

Experimenter and subject errors were scored as in Experiment 1 . The mean reaction times and mean percentage of subject errors for all of the experimental conditions are displayed in Table 1 . An analysis of variance on the reaction times indicated that the effect of context condition was significant $[F(2,62)=8.38$, $\mathrm{p}<.0011$, but neither the main effect of target type $[\mathrm{F}(1,31)=3.09]$ nor the Context Condition by Target Type interaction $(F<1)$ attained statistical significance. Averaged across target type, the overall context effect was approximately $20 \mathrm{msec}$ (small overall context effects were also present in the error rates), a value very similar to that obtained in Experiment 1. Unlike Experiment 1 , the contextual effect in Experiment 2 was manifested exclusively as facilitation. Planned comparisons indicated that the 28-msec facilitation effect in both the word and nonword conditions was significant $(p<.01)$. The facilitation dominance of Experiment 2 was thus consistent with previous experiments that have employed this paradigm (Stanovich \& West, 1979, 1981).

\section{EXPERIMENT 3}

In order to assess the generality of the results obtained in Experiments 1 and 2, an additional experiment that employed completely different methods of target initiation and context processing was carried out. In the previous experiments, the subject read the context aloud and the experimenter controlled target presentation. In Experiment 3, the subject read the context silently and the target onset occurred at a fixed interval after context onset.

\section{Method}

The subjects were 16 undergraduate students recruited through a subject pool at Oakland University. The stimuli and apparatus used in Experiment 2 were employed in Experiment 3. The design and counterbalancing were also the same as those in Experiment 2. Experiment 3 differed from the previous experiments in that subjects were told to read the contexts silently before naming the target modifier. The targets were always 
presented $2,500 \mathrm{msec}$ after the onset of the context. The 2,500msec context exposure duration was chosen as a rough estimate (based on data from several subjects who were timed while reading lists of the contexts) of the average amount of time that the subjects in the previous experiments had spent reading the contexts aloud.

\section{Results}

The mean reaction times and mean percentage of errors for all of the experimental conditions are dis. played in Table 1. An analysis of variance on the reaction times indicated that the effect of context condition was significant $[F(2,30)=7.09, p<.005]$, but neither the main effect of target type $(\mathrm{F}<1)$ nor the Context Condition by Target Type interaction $(\mathrm{F}<1)$ attained statistical significance. Collapsed across context conditions, the word and nonword target types had mean reaction times that were very similar. Consistent with the findings of the first two experiments, the lexical status of the terminal word did not affect target naming.

As in Experiment 2, the significant effect of context condition was manifested entirely as contextual facilitation. Planned comparisons indicated that the $36-\mathrm{msec}$ and the 34-msec facilitation effects were both significant at the .025 level. The nonword condition showed an unexpected 22-msec advantage for incongruous contexts over neutral contexts. However, this $22-\mathrm{msec}$ effect did not reach statistical significance $(.10<p<.15)$. More important, the higher error rate displayed by the incongruous condition probably accounts for its reaction time advantage.

\section{GENERAL DISCUSSION}

All three experiments produced consistent evidence on the issue of parafoveal priming during reading. The results indicated that the semantic characteristics of the word immediately to the right of the word being fixated do not influence the processing of the fixated word. This finding considerably simplifies the problem faced by researchers investigating the effects of context on ongoing word recognition during reading. At least as regards the effect of semantic context, it appears that researchers need be concerned only with contextual information that occurs before the fixated word. ${ }^{1}$

The results reported contradict Underwood's (1981) conjecture that the semantic characteristics of words in the right parafovea can affect ongoing processing during reading. However, we are left with the problem of trying to reconcile the present results with Underwood's $(1976,1977,1980,1981)$ finding that stimulus recognition was influenced by the semantic characteristics of words presented to the right of fixation. One obvious methodological difference was that Underwood's experiments did not include the presentation of a sentence context. The processing of the target in his experiments was not embedded in ongoing sentence processing. Instead, subjects had to respond only to a single target stimulus on every trial. Also, the tasks used by Underwood (category naming, picture naming, paired associate response time) were quite different from that employed in the present experiments, and whether a parafoveal prime facilitated or inhibited the response to the foveal stimulus in his experiments depended on the task employed (compare Underwood, 1980, and Underwood, 1981).

Perhaps a more important difference concerns the relationship between the targets and parafoveal primes. Underwood purposely chose his stimulus pairs (which were noun-noun pairs rather than modifier-noun pairs) to be highly related. In his 1976 paper, the examples of stimulus pairs given in the Methods section were chair-table, boat-sail, and lemon-juice. In the 1981 paper, in which a category-naming task was employed, the stimuli were the five most popular responses (taken from the Battig \& Montague, 1969, norms) from five highly overlearned categories (colors, animals, clothing, body parts, and methods of transport). Even though the stimuli used in Experiments 2 and 3 of the present paper were constructed to have stronger relationships than those used in Experiment 1, they were probably still well below Underwood's stimuli in terms of semantic relatedness. This is simply because of the constraints imposed by the fact that the last two words had to make the sentence grammatical and also be meaningful completions of the Stanovich and West (1981) sentences. Thus, it might be conjectured that semantic priming from parafoveal words can occur if the prime and target are strong associates, but that such priming does not normally occur for the more moderate relationships found in natural text. To avoid any misunderstanding regarding this hypothesis, it should be pointed out that we are not arguing that the sentences used in Experiments 2 and 3 were representative of the average text that is read by fluent adults. They were most definitely unrepresentative in a number of ways, the most relevant being that the last two words had an unusually high degree of semantic association. The point is that the materials used in the experiments were biased in favor of observing parafoveal priming effects. If such effects do not occur with the materials of Experiments 2 and 3, it is highly unlikely that they are much of a factor in normal reading. ${ }^{2}$

The results of the three experiments also lead to several conclusions regarding the effect of a sentence context on the recognition of a nonterminal word. The findings indicated that sentence congruity can affect the processing of a nonterminal word that was not chosen for its high predictability. There are, however, some important caveats to this general conclusion. First, the size of the context effect (averaging $19 \mathrm{msec}$ across experiments) was smaller than that observed in previous experiments that, using similar methodologies, have investigated the effect of a sentence context on the processing of terminal nouns that were either highly 
related to words in the context. ${ }^{3}$ The hypothesis discussed earlier, that the size of the effects previously observed would not generalize to other sentence positions, appears to have received some support. A second and related point is that the particular paradigm employed serves to, if anything, overestimate the magnitude of context effects. Mitchell (1982; Mitchell \& Green, 1978) has argued that the paradigms used by Fischler and Bloom (1979), Schuberth and Eimas (1977), and Stanovich and West (1981) all introduce an unusually long interval between the reading of the sentence context and the target word (see also McConkie \& Zola, 1981). This extra time may allow the subject to employ conscious prediction strategies that would be precluded in normal reading due to the speed of ongoing word recognition. Thus, the $19-\mathrm{msec}$ figure obtained probably represents an upper bound on the magnitude of the context effect on the type of target word sampled in these experiments. In short, while our results should not be interpreted as questioning the theoretical utility of previous sentence context experiments (for example, regarding tests of various models of word recognition, perceptual identification, and semantic memory), they do suggest caution in extrapolating the magnitudes of observed experimental effects to the actual reading situation.

Specifying the mechanism that was responsible for the contextual effects that were observed requires some discussion of the inconsistencies in the pattern of the effects across the three experiments. Experiment 1 showed a pattern of inhibition dominance, whereas Experiments 2 and 3 showed a pattern of facilitation dominance. According to the traditional interpretation of these patterns in terms of the Posner-Snyder (1975a, 1975b) two-process theory of expectancy (Neely, 1976, 1977; Stanovich \& West, 1979, 1981) facilitation dominance is indicative of a context effect that is caused by the automatic spread of activation in semantic memory. Inhibition is caused by an attentional expectancy strategy. However, according to this framework, inhibition should be accompanied by facilitation. Thus, given this framework, the results of Experiment 1 are inexplicable. The results are also anomalous when viewed in the context of the rest of the empirical literature. In over a dozen sentence context experiments employing the naming paradigm (Stanovich, 1981; Stanovich \& West, 1979, 1981, Note 7, Note 8; Stanovich, West, \& Feeman, 1981; West \& Stanovich, 1978, 1982), we have never observed a pattern of inhibition dominance. Thus, due to the theoretical and empirical consistency of the results of Experiments 2 and 3 and the theoretical and empirical inconsistency of the results of Experiment 1 , we feel reasonably safe in putting greater reliance on the former when searching for a theoretical mechanism to explain the small context effect that was obtained. Not surprisingly, we are drawn to automatic spreading activation as a likely mechanism. No previous experiments with this paradigm (e.g., Stanovich \& West,
1979, 1981; West \& Stanovich, 1982) have yielded evidence indicating that an attentional prediction process was responsible for the context effects produced when adults read undegraded material. Indeed, investigators who have used quite different methodologies to attack these same issues have also argued against conscious prediction as the mechanism responsible for the context effects observed in their paradigms (e.g., Fischler \& Bloom, 1979; Fischler, Note 9).

The results of the three experiments, in conjunction with the findings of Mitchell and Green (1978), Gough (Note 1), and Alford (Note 3), question the view of the fluent reader provided by the top-down models. These models see the fluent reader as minimally sampling visual features in order to confirm hypotheses or to choose among a limited set of alternatives consistent with the previous context. It is this minimal sampling of visual features based on contextual redundancy that accounts in large part for the good reader's fluency. However, the average magnitude of contextual effects on ongoing word recognition do not appear to be large enough to allow this mechanism to be a major determinant of reading fluency. In addition, the mechanism involved does not seem to be one of word prediction ${ }^{4}$ but, instead, appears to be a passive process of spreading activation. This may help to explain why there is mounting evidence that top-down models do not give an accurate account of individual differences in reading ability (Stanovich, 1980) or the performance patterns of fluent readers (Ehrlich \& Rayner, 1981; McConkie \& Zola, 1981; Mitchell, 1982; Mitchell \& Green, 1978; Rayner \& Slowiaczek, 1981; Gough, Note 1; Gough et al., Note 5).

It is, of course, possible to counter the above argument with the claim that the reader's hypotheses about upcoming text concern meaning, and not individual words. However, if readers do not predict words, then these models are moot on the question of contextual effects on lexical access. If this tact is taken, it means that the context effects that top-down theorists are concerned with are postlexical, that is, effects on comprehension processes that occur after a word has been recognized (the existence of this type of effect is not disputed by any theorist that we know of). It would mean giving up the oft-stated claims for "hypothesisdriven" feature extraction and lexical access during reading (e.g., Goodman, 1976; Smith, 1978).

\section{REFERENCE NOTES}

1. Gough, P. B. Context, expectation, and word recognition. Paper presented at the meeting of the Midwestern Psychological Association, Detroit, May 1981.

2. Mitchell, D. C., \& Green, D. W. Contextual effects in continuous reading. Paper presented at the British Psychological Society Conference on Reading, Exeter University, March 1980.

3. Alford, J. A. The interaction of sentential context and stimulus quality in word recognition. Paper presented at the meeting of the Midwestern Psychological Association, Chicago, May 1979. 
4. Alford, J. A. Predicting predictability: Identification of sources of contextual constraint on words in text. Paper presented at the meeting of Midwestern Psychological Association, St. Louis, May 1980.

5. Gough, P. B., Alford, J. A., \& Holley-Wilcox, P. Words and contexts. Paper presented at the meeting of the National Reading Conference, St. Petersburg Beach, Florida, November 1978.

6. Kiger, J. I., \& Glass, A. L. Backwards priming in the lexical decision task. Paper presented at the meeting of the Eastern Psychological Association, New York, April 1981.

7. Stanovich, K. E., \& West, R. F. On priming by a sentence context. Manuscript in preparation, 1982.

8. Stanovich, K. E., \& West, R. F. The stability and generality of sentence context effects on word recognition speed. Paper presented at the annual meeting of the Psychonomic Society, Philadelphia, November 1981.

9. Fischler, I. Studies of the effects of sentence contexts on lexical decision speed: Implications for models of word recognition and reading skill. Paper presented at the meeting of the Midwestern Psychological Association, Detroit, May 1981.

\section{REFERENCES}

Abonn, M., Rubenstein, H., \& Sterling, T. D. Sources of contextual constraint upon words in sentences. Journal of Experimental Psychology, 1959, 57, 171-180.

Battig, W. R., \& Montague, W. E. Category norms for verbal items in 56 categories: A replication and extension of Connecticut norms. Journal of Experimental Psychology Monographs, 1969, 80(3, Pt. 2).

Becker, C. A., \& Kitlion, T. H. Interaction of visual and cognitive effects in word recognition. Journal of Experimental Psychology: Human Perception and Performance, 1977, 3, 389-401.

Bradshaw, J. L. Peripherally presented and unreported words may bias the perceived meaning of a centrally fixated homograph. Journal of Experimental Psychology, 1974, 103, 1200 1202.

Cosky, M. J. The role of letter recognition in word recognition. Memory \& Cognition, 1976, 4, 207-214.

Ehrlich, S. F., \& Rayner, K. Contextual effects on word perception and eye movements during reading. Journal of Verbal Learning and Verbal Behavior, 1981, 20, 641-655.

Fischle r, I. Associative facilitation without expectancy in a lexical decision task. Journal of Experimental Psychology: Human Perception and Performance, 1977, 3, 18-26.

Fischler, I., \& Bloom, P. A. Automatic and attentional processes in the effects of sentence contexts on word recognition. Journal of Verbal Learning and Verbal Behavior, 1979, 18, $1-20$.

Fischler, I., \& Bloom, P. A. Rapid processing of the meaning of sentences. Memory \& Cognition, 1980, 8, 216-225.

Fischler, I., \& Goodman, G. O. Latency of associative activation in memory. Journal of Experimental Psychology: Human Perception and Performance, 1978, 4, 455-470.

Fowler, C. A., Wolford, G., Slade, R., \& Tassinary, L. Lexical access with and without awareness. Journal of Experimental Psychology: General, 1981, 110, 341-362.

Frederiksen, J. R., \& Kroll, J. F. Spelling and sound: Approaches to the internal lexicon. Journal of Experimental Psychology: Human Perception and Performance, 1976, 2, 361-379.

Goodman, K. S. Reading: A psycholinguistic guessing game. In H. Singer \& R. Ruddell (Eds.), Theoretical models and processes of reading. Newark, Del: International Reading Association, 1976.

Hochbero, J. Components of literacy: Speculations and exploratory research. In H. Levin \& J. Williams (Eds.), Basic studies in reading. New York: Basic Books, 1970.
Inhoff, A. W. Parafoveal word perception: A further case against semantic preprocessing. Journal of Experimental Psy. chology: Human Perception and Performance, 1982, 8, 137. 145 .

Inhoff, A. W., \& Rayner, K. Parafoveal word perception: A case against semantic processing. Perception \& Psychophysics, 1980, 27, 457-464.

KLEIMAN, G. M. Sentence frame contexts and lexical decisions: Sentence-acceptability and word-relatedness effects. Memory \& Cognition, 1980, 8, 336-344.

Levin, H., \& Kaplan, E. L. Grammatical structure and reading. In $\mathrm{H}$. Levin \& J. Williams (Eds.), Basic studies in reading. New York: Basic Books, 1970.

MARCEL, T. Unconscious reading: Experiments on people who do not know they are reading. Visible Language, 1978, 12, 392-404.

McCauley, D., Parmelee, C. M., Sperber, R. D., \& Carr, T. H. Early extraction of meaning from pictures and its relation to conscious identification. Journal of Experimental Psychology: Human Perception and Performance, 1980, 6, 265276.

McClelland, J. L., \& O'Regan, J. K. Expectations increase the benefit derived from parafoveal visual information in reading words aloud. Journal of Experimental Psychology: Human Perception and Performance, 1981, 7, 634-644.

McConkie, G. W. On the role and control of eye movements in reading. In P. A. Kolers, M. E. Wrolstad, \& H. Bouma (Eds.), Processing of visual language (Vol. 1). New York: Plenum, 1979.

McConkie, G. W., \& ZolA, D. Language constraints and the functional stimulus in reading. In A. M. Lesgold \& C. A. Perfetti (Eds.), Interactive processes in reading. Hillsdale, N.J: Erlbaum, 1981.

MerikLe, P. M. Unconscious perception revisited. Perception \& Psychophysics, 1982, 31, 298-301.

Meyer, D. E., \& Schvaneveldt, R. W. Facilitation in recognizing pairs of words: Evidence of a dependence between retrieval operations. Journal of Experimental Psychology, 1971, 90, 227-234

Meyer, D. E., Schvaneveldt, R. W., \& Ruddy, M. G. Loci of contextual effects on word recognition. In P. M. A. Rabbitt \& S. Dornic (Eds.), Attention and performance V. New York: Academic Press, 1975 .

Mille R, G. R., \& Coleman, E. B. A set of thirty-six prose passages calibrated for complexity. Journal of Verbal Learning and Verbal Behavior, 1967, 6, 851-854.

MitcheLl, D. C. The process of reading: $A$ cognitive analysis of fluent reading and learning to read. New York: Wiley, 1982.

Mitchell, D. C., \& Green, D. W. The effects of context and content on immediate processing in reading. Quarterly Journal of Experimental Psychology, 1978, 30, 609-636.

NeELy, J. H. Semantic priming and retrieval from lexical memory: Evidence for facilitatory and inhibitory processes. Memory \& Cognition, 1976, 4, 648-654.

NeELy, J. H. Semantic priming and retrieval from lexical memory: Roles of inhibitionless spreading activation and limitedcapacity attention. Journal of Experimental Psychology: General, 1977, 106, 226-254.

PAAP, K. R., \& Newsome, S. L. Parafoveal information is not sufficient to produce semantic or visual priming. Perception \& Psychophysics, 1981, 29, 457-466.

Perfetti, C. A., Goldman, S. R., \& Hogaboam, T. W. Reading skill and the identification of words in discourse context. Memory \& Cognition, 1979, 7, 273-282.

Philpott, A., \& Wilding, J. Semantic interference from subliminal stimuli in a dichotic viewing situation. British Journal of Psychology, 1979, 70, 559-563.

Posner, M. I., \& SNyder, C. R. R. Attention and cognitive control. In R. Solso (Ed.), Information processing and cognition: The Loyola symposium. Hillsdale, N.J: Erlbaum, 1975. (a)

Posner, M. I., \& SNyder, C. R. R. Facilitation and inhibition in the processing of signals. In P. M. A. Rabbitt \& S. Dornic 
(Eds.), Attention and performance $V$. New York: Academic Press, 1975. (b)

Rayner, K., Inhorf, A. W., Monrison, R. E., Slowiaczex, M. L., \& Bertera, J. H. Masking of foveal and parafoveal vision during eye fixations in reading. Journal of Experimental Psychology: Human Perception and Performance, 1981, 7, 167-179.

Rayner, K., McConkie, G. W., \& Zola, D. Integrating information across eye movements. Cognitive Psychology, 1980, 12, 206-226.

RAYNER, K., \& Slowinczer, M. L. Expectations and parafoveal information in reading: Comments on McClelland and O'Regan. Journal of Experimental Psychology: Human Perception and Performance, 1981, 7, 645-651.

Richardson, J. T. E. The effects of stimulus attributes upon latency of word recognition. British Journal of Psychology, 1976, 67, 315-325.

Rugenstern, H., \& Aborn, M. Learning, prediction, and readability. Journal of Applied Psychology, 1958, 42, 28-32.

Schiepens, C. Response latency and accuracy in visual word recognition. Perception \& Psychophysics, 1980, 27, 71-81.

Schuberth, R. E., \& Eimas, P. D. Effects of context on the classification of words and nonwords. Journal of Experimental Psychology: Human Perception and Performance, 1977, 3, 27-36.

Schuberth, R. E., Spoehr, K. T., \& Lane, D. M. Effects of stimulus and contextual information on the lexical decision process. Memory \&ognition, 1981, 9, 68-77.

SchyaneveldT, R. W., \& McDonald, J. E. Semantic context and the encoding of words: Evidence for two modes of stimulus analysis. Journal of Experimental Psychology: Human Perception and Performance, 1981, 7, 673-687.

Shapter, W. O., \& LaBerge, D. Automatic semantic processing of unattended words. Journal of Verbal Learning and Verbal Behavior, 1979, 18, 413-426.

Sмтт,, F. Understanding reading. New York: Holt, Rinehart \& Winston, 1978.

Stanovich, K. E. Toward an interactive-compensatory model of individual differences in the development of reading fluency. Reading Research Quarterly, 1980, 16, 32-71.

Stanovich, K. E. Attentional and automatic context effects in reading. In A. M. Lesgold \& C. A. Perfetti (Eds.), Interactive processes in reading. Hillsdale, N.J: Erlbaum, 1981.

Stanovich, K. E., \& West, R. F. Mechanisms of sentence context effects in reading: Automatic activation and conscious attention. Memory \& Cognition, 1979, 7, 77-85.

Stanovich, K. E., \& WEst, R. F. The effect of sentence context on ongoing word recognition: Tests of a two-process theory. Journal of Experimental Psychology: Human Perception and Performance, 1981, 7, 658-672.

Stanovich, K. E., Wegt, R. F., \& Feeman, D. J. A longitudinal study of sentence context effects in second-grade children: Tests of an interactive-compensatory model. Journal of Experimental Child Psychology, 1981, 32, 185-199.

UNDERWOGD, G. Semantic interference from unattended printed words. British Journal of Psychology, 1976, 67, 327-338.

UNDERwOOD, G. Attention, awareness, and hemispheric differences in word recognition. Neuropsychologia, 1977, 15, 61-67.

UNDERWOOD, G. Attention and the non-selective lexical access of ambiguous words. Canadian Journal of Psychology, 1980, 34, 72-76.

UNDERWOOD, G. Lexical recognition of embedded unattended words: Some implications for reading processes. Acta Psychologica, 1981, 47, 267-283.

West, R. F., \& Stanovich, K. E. Automatic contextual facilitation in readers of three ages. Child Development, 1978, 49 , 717-727.

West, R. F., \& Stanovich, K. E. Source of inhibition in experiments on the effect of sentence context on word recognition. Journal of Experimental Psychology: Learning, Memory, and Cognition, 1982, 8, 385-399.

\section{NOTES}

1. Of course, part of the contextual information may be visual features of the fixated word that were picked up parafoveally on the previous fixation. As mentioned in the introduction, there now exist some useful data on this issue (e.g., Rayner, McConkie, \& Zola, 1980).

2. Also, the fact that where the subject fixated was not under experimental control would also tend to bias the results in favor of observing parafoveal effects. If the subject sometimes fixated the terminal noun before the lexical access of the modifier was complete then, given previous priming results, this should have affected modifier naming.

3. A more specific statement is in order regarding the magnitude of the context effects to be expected for the modifier stimuli, based on previous results from this paradigm with sentence-final stimuli. Previous work has established that the magnitude of the overall context effect is directly related to the difficulty (i.e., naming latency) of the target word (Perfetti, Goldman, \& Hogaboam, 1979; Stanovich, 1981; Stanovich \& West, 1981; Stanovich, West, \& Feeman, 1981; West \& Stanovich, 1982). Since in naming tasks word length has the most potent influence on response time (Cosky, 1976; Frederiksen \& Kroll, 1976; Richardson, 1976), it will be useful to examine this variable. The modifiers in Experiments 2 and 3 had a mean length of 6.4 letters and an average naming time of approximately $600 \mathrm{msec}$ in the neutral condition. The easy words employed by Stanovich and West (1981) had a mean length of 5.0 letters, and the difficult words had a mean length of 7.4 letters. Across a series of experiments employing the same apparatus and stimulus conditions as Experiments 2 and 3 (West \& Stanovich, 1982; Stanovich \& West, Note 7, Note 8), the mean naming time for the easy words was approximately $550 \mathrm{msec}$ and the mean naming time for the difficult words was approximately $710 \mathrm{msec}$ in the neutral sentence condition. Thus, both in terms of word length and in actual naming latency, the difficulty of the modifiers is intermediate between the easy and difficult words in the appendix of Stanovich and West (1981). The latter two sets, when used as sentence-final targets in the Stanovich and West (1981) sentences, resulted in average overall context effects of approximately $30 \mathrm{msec}$ and $75 \mathrm{msec}$, respectively (West \& Stanovich, 1982; Stanovich \& West, Note 7, Note 8). The effect observed for the modifiers (approximately $19 \mathrm{msec}$ ) is not a value intermediate between these figures. In fact, it is out of the range altogether.

4. This problem with the top-down models is not obviated by switching the terminology from "prediction" to "reduction of alternatives through the use of redundancy," unless a mechanism can be specified in the latter case.

(Received for publication November 3, 1981; revision accepted August 2, 1982.) 